\title{
SONOGRAPHY CHARACTERISATION AND HISTOPATHOLOGICAL CORRELATION OF CERVICAL LYMPHADENOPATHY IN RURAL ADULT POPULATION OF CENTRAL INDIA
}

\author{
Sheetal Singh', Amlendu Nagar², Pramod Sakhi³, Kumud Julka4, Vishal Mulchandani ${ }^{5}$ \\ ${ }^{1}$ Associate Professor, Department of Radiodiagnosis, Index Medical College, Indore, Madhya Pradesh. \\ ${ }^{2}$ Associate Professor, Department of Radiodiagnosis, Index Medical College, Indore, Madhya Pradesh. \\ ${ }^{3}$ Professor, Department of Radiodiagnosis, Index Medical College, Indore, Madhya Pradesh. \\ ${ }_{4}^{4}$ Associate Professor, Department of Radiodiagnosis, Index Medical College, Indore, Madhya Pradesh. \\ 5 Resident, Department of Radiodiagnosis, Index Medical College, Indore, Madhya Pradesh.
}

\section{ABSTRACT}

\section{BACKGROUND}

Various diseases may cause cervical lymphadenopathy such as lymphoma, metastasis and chronic infections like tuberculosis. Accurate detection of malignant involvement is helpful in diagnosis, staging and planning for treatment in malignancy. Ultrasound is a useful method to localise and characterise LNs for its morphological features like size, shape, margin, echotexture, status of hilum, necrosis and calcification. Colour Doppler is useful to see pattern of vascularity and assessment of flow impedance.

The aim of our study was to estimate the role of high resolution sonography in differentiation of benign and malignant cervical lymph node with histopathological findings as the reference standard.

\section{MATERIALS AND METHODS}

90 patients were included in this prospective study; total 110 lymph nodes were evaluated by sonography and correlated later with histopathology. All the patients included in study were from rural background and above 18 years of age. Roundness index, absence of hilum, hypoechoic echotexture and ill-defined borders were taken as criteria for malignant involvement of LNs on grey scale and RI > 0.8 and PI > 1.5 for assessment of vascularity.

\section{RESULTS}

Out of 110 lymph nodes, 25\% (27/110) were found to be malignant and 75\% (83/110) were benign. Roundness index, markedly hypoechoic echotexture, absence of hilum and peripheral/mixed vascular pattern revealed sensitivity of $96 \%, 74 \%, 92 \%$ and $85 \%$; and positive predictive value $66 \%, 86 \%, 71 \%$ and $63 \%$ respectively.

\section{CONCLUSION}

High resolution ultrasound is useful in differentiation of benign from malignant cervical lymph nodes. Ultrasound criteria of roundness index, absence of hilum and vascular pattern revealed good sensitivity, specificity and accuracy in differentiation of benign from malignant lymph nodes; however, in view of high negative predictive value as well no individual ultrasound feature was found accurate in diagnosis of malignant cervical lymphadenopathy requiring guided FNAC for further differentiation.

\section{KEYWORDS}

Lymph Nodes, Benign, Malignant, High Resolution Ultrasonography, HRUS, Roundness Index, Hilum, Vascular Pattern, Marked Hypoechoic, RI, PI.

HOW TO CITE THIS ARTICLE: Singh S, Nagar A, Sakhi P, et al. Sonography characterisation and histopathological correlation of cervical lymphadenopathy in rural adult population of Central India. J. Evolution Med. Dent. Sci. 2017;6(24):1975-1980, DOI: $10.14260 /$ Jemds/2017/433

\section{BACKGROUND}

Cervical lymphadenopathy is common in clinical practice. In our country, chronic infectious diseases like tuberculosis is a leading cause for non-malignant lymphadenopathy, while metastasis and lymphoma are known causes of malignant cervical lymphadenopathy.

Financial or Other, Competing Interest: None.

Submission 23-01-2017, Peer Review 10-03-2017,

Acceptance 18-03-2017, Published 23-03-2017.

Corresponding Author:

Dr. Sheetal Singh,

214, A3 Milan Heights,

Near Agrawal Public School,

Bicholi Mardana

Indore-452016,

Madhya Pradesh.

E-mail: Sheetalsinghdr@gmail.com

DOI: $10.14260 /$ jemds $/ 2017 / 433$

\section{(c) (i) $\$$}

With the rising incidence of head and neck cancer in rural India, the incidence of metastatic cervical lymphadenopathy is also increasing. Diagnosis of malignant cervical lymphadenopathy is important in patients with suspected malignant neoplasm and also for pre-treatment staging and therapeutic planning with proven primary head and neck carcinoma. A metastatic lymph node reduces the 5 year survival rate by $50 \%$ and presence of another metastatic lymph node on contralateral side further reduces the 5-year survival rate to $25 \%{ }^{1}$

Normal lymph nodes appear different from abnormal lymph nodes in ultrasound imaging. The histologic variations observed in patients with lymph nodal diseases are used to show the morphological changes in lymph nodes shown by grey scale High Resolution Sonography (HRUS).2 Ultrasound is a useful imaging modality for assessment of cervical lymphadenopathy when combined with FNAC specificity increases up to $93 \% .^{3}$ 


\section{MATERIALS AND METHODS}

A prospective study was done in Index Medical College in Department of Radiodiagnosis. Total 110 lymph nodes from 90 patients were evaluated with HRUS over a period of 12 months (From October 2015 to 30 October 2016) and correlated subsequently with Histopathological Examination (HPE). HRUS of neck was performed by SIEMENS ACUSON X300 with High resolution linear array probe at 5 to $10 \mathrm{MHz}$. All the patients included in study were from rural background and above 18 years of age. All lymph nodes included in this study were undergone for USG guided FNAC/Core Needle biopsy/excision biopsy. HRUS features of lymph nodes included number, size, shape, presence or absence of hilum, echogenicity, margins, structural changes and perinodal soft tissue oedema. Doppler criteria include vascular pattern, number of vascular pedicle and impedance values (RI, PI).

Statistical Method- The obtained data was entered in Microsoft Excel 2016 for Windows. Frequencies (n) and percentages (\%) of variables were calculated. Results were obtained and tabulated using Microsoft Excel spreadsheet. Also, Sensitivity, Specificity, Accuracy, Positive and Negative likelihood ratios were calculated. Data analyses were performed using version 17.0 of the MedCalc software program (MedCalc Software BVBA, Acacialaan, Ostend, Belgium).

\section{RESULTS}

Individual HRUS feature for malignancy (according to classical criteria to differentiate malignant and benign lymph nodes) was compared with the histopathological findings. The classical criteria used to separate benign lymph nodes from malignant lymph nodes is shown in Table $1 .{ }^{4}$

\begin{tabular}{|c|c|c|}
\hline B-Scan Criteria & Benign & Malignant \\
\hline Size & Small & Larger \\
\hline Shape & Oval & Rounded \\
\hline Hilum & Present & Absent \\
\hline Echogenicity & $\begin{array}{c}\text { Moderate or Low } \\
\text { Hypoechoic }\end{array}$ & $\begin{array}{c}\text { Marked } \\
\text { Hypoechoic }\end{array}$ \\
\hline Margins & Sharp & $\begin{array}{l}\text { Irregular, Blurred, } \\
\text { Angular, Invasive }\end{array}$ \\
\hline \multicolumn{3}{|l|}{ Structural Changes } \\
\hline Focal cortical nodules & - & - \\
\hline Intranodal necrosis & Absent & Present \\
\hline Reticulation & - & - \\
\hline Calcification & - & - \\
\hline Matting & -- & - \\
\hline Soft tissue oedema & May be present & Absent \\
\hline \multicolumn{3}{|l|}{ Doppler Criteria } \\
\hline Flow & Absent & Present \\
\hline Vessel Location & Central & Peripheral \\
\hline Vascular Pedicle & Single & Multiple \\
\hline Vascular Pattern & Regular & Chaotic \\
\hline Impedance value & Low & High \\
\hline
\end{tabular}

According to Gray scale features shown in Table 2, total 110 lymph nodes were evaluated, approximately 25\% (27/110) lymph nodes were found to be positive for malignancy on HPE and $75 \%(83 / 110)$ were benign. Small size and oval shaped were found more in benign lymph nodes, whereas large size and round shaped lymph nodes were associated more with malignancy. Markedly, hypoechoic echotexture, ill-defined margins and absence of hilum were observed in malignant LN. Only one calcified lymph node showed malignancy (Table 3). On colour Doppler study, malignant lymph nodes showed peripheral and mixed vascularity pattern with and high RI and PI values (Table 4).

\begin{tabular}{|c|c|c|c|c|c|c|c|c|c|}
\hline $\begin{array}{c}\text { Ultrasound } \\
\text { Characteristic }\end{array}$ & Criteria & $\begin{array}{l}\text { No. of Lymph } \\
\text { Nodes }\end{array}$ & $\begin{array}{l}\text { Malignant } \\
\text { on HPE }\end{array}$ & $\begin{array}{c}\text { Benign on } \\
\text { HPE }\end{array}$ & PPV \% & NPV \% & SN \% & SP \% & Acc \% \\
\hline \multirow{2}{*}{ Size } & $<1.0 \mathrm{~cm}$ & 14 & 3 & 11 & - & - & - & - & - \\
\hline & $>1.0 \mathrm{~cm}$ & 96 & 27 & 72 & 25 & 78 & 89 & 13 & 31 \\
\hline \multirow{2}{*}{$\begin{array}{l}\text { Shape/Roundness } \\
\text { Index } \\
\end{array}$} & $>1.5$ (oval) & 71 & 1 & 70 & - & - & - & - & - \\
\hline & $<1.5$ (round) & 39 & 26 & 13 & 66 & 98 & 96 & 84 & 87 \\
\hline \multirow[t]{2}{*}{ Echogenicity } & $\begin{array}{l}\text { Low/Moderate } \\
\text { Hypoechoic }\end{array}$ & 87 & 7 & 80 & - & - & - & - & - \\
\hline & Marked Hypoechoic & 23 & 20 & 3 & 86 & 91 & 74 & 96 & 90 \\
\hline \multirow{2}{*}{ Hilum } & Present & 76 & 2 & 74 & - & - & - & - & - \\
\hline & Absent & 34 & 25 & 9 & 71 & 97 & 92 & 89 & 90 \\
\hline \multirow{2}{*}{ Margins } & Well-Defined & 88 & 19 & 69 & - & - & - & - & - \\
\hline & Ill-Defined & 12 & 7 & 5 & 58 & 78 & 26 & 83 & 69 \\
\hline \multicolumn{10}{|c|}{ Table 2. Grey Scale Features } \\
\hline
\end{tabular}

\begin{tabular}{|c|c|c|c|c|c|c|c|c|c|}
\hline $\begin{array}{c}\text { Ultrasound } \\
\text { Characteristics }\end{array}$ & Criteria & $\begin{array}{c}\text { No. of } \\
\text { Lymph Nodes }\end{array}$ & $\begin{array}{c}\text { Malignant on } \\
\text { HPE }\end{array}$ & $\begin{array}{c}\text { Benign on } \\
\text { HPE }\end{array}$ & PPV \% & NPV \% & SN \% & SP \% & ACC \% \\
\hline \multirow{2}{*}{ Calcification } & Absent & 96 & 26 & 70 & - & - & - & - & - \\
\cline { 2 - 10 } & Present & 14 & 01 & 13 & 7 & 73 & 4 & 81 & 64 \\
\hline \multirow{2}{*}{ Necrosis } & Absent & 85 & 21 & 64 & - & - & - & - & - \\
\cline { 2 - 10 } & Present & 25 & 6 & 19 & 24 & 75 & 22 & 77 & 64 \\
\hline $\begin{array}{c}\text { Perilymph Nodal } \\
\text { Oedema }\end{array}$ & Absent & 97 & 26 & 71 & - & - & - & - & - \\
\cline { 2 - 10 } & Present & 13 & 1 & 12 & 7 & 73 & 4 & 85 & 65 \\
\hline \multicolumn{2}{|c|}{ Table 3. Internal Structural Changes } \\
\hline
\end{tabular}




\begin{tabular}{|c|c|c|c|c|c|c|c|c|c|}
\hline $\begin{array}{l}\text { Colour Doppler } \\
\text { Characteristics }\end{array}$ & Criteria & $\begin{array}{c}\begin{array}{c}\text { No. of Lymph } \\
\text { Nodes }\end{array} \\
\end{array}$ & \begin{tabular}{|c|}
$\begin{array}{c}\text { Malignant on } \\
\text { HPE }\end{array}$ \\
\end{tabular} & $\begin{array}{l}\text { Benign } \\
\text { on HPE }\end{array}$ & PPV \% & NPV \% & SN \% & SP \% & ACC \% \\
\hline \multirow{3}{*}{ Vascular Pattern } & Central & 74 & 4 & 70 & - & - & - & - & - \\
\hline & Peripheral & 27 & 20 & 7 & 63 & 94 & 85 & 84 & 84 \\
\hline & Mixed & 9 & 3 & 6 & - & - & - & - & - \\
\hline \multirow{2}{*}{$\begin{array}{l}\text { D. Indices } \\
\text { RI }\end{array}$} & $<0.8$ & 73 & 5 & 68 & - & - & - & - & - \\
\hline & $>0.8$ & 37 & 22 & 15 & 59 & 93 & 81 & 82 & 82 \\
\hline \multirow[t]{2}{*}{ PI } & $<1.4$ & 76 & 6 & 70 & - & - & - & - & - \\
\hline & $>1.4$ & 34 & 21 & 13 & 61 & 92 & 78 & 84 & 83 \\
\hline \multicolumn{10}{|c|}{ Table 4} \\
\hline
\end{tabular}

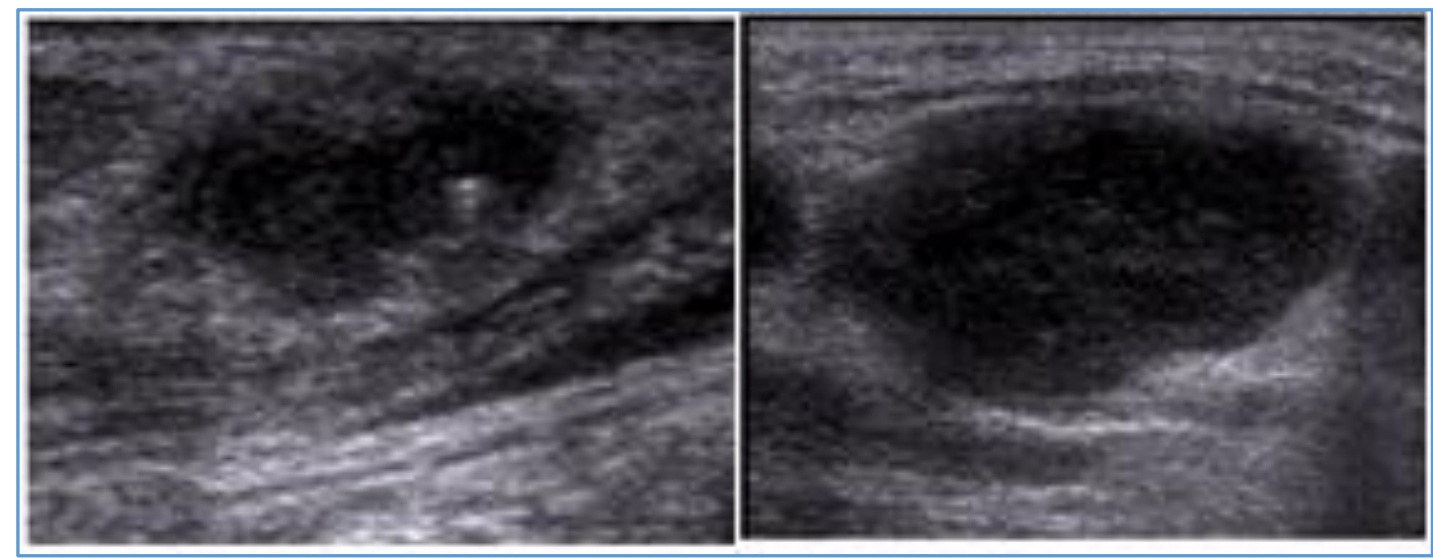

Figure 1A \& B. Tubercular Lymph Node reveals Necrosis with Eccentric Calcification (Figure A) and markedly Hypoechoic Lobulated IIl-Defined Borders Lymph Node in Malignancy (Figure B)

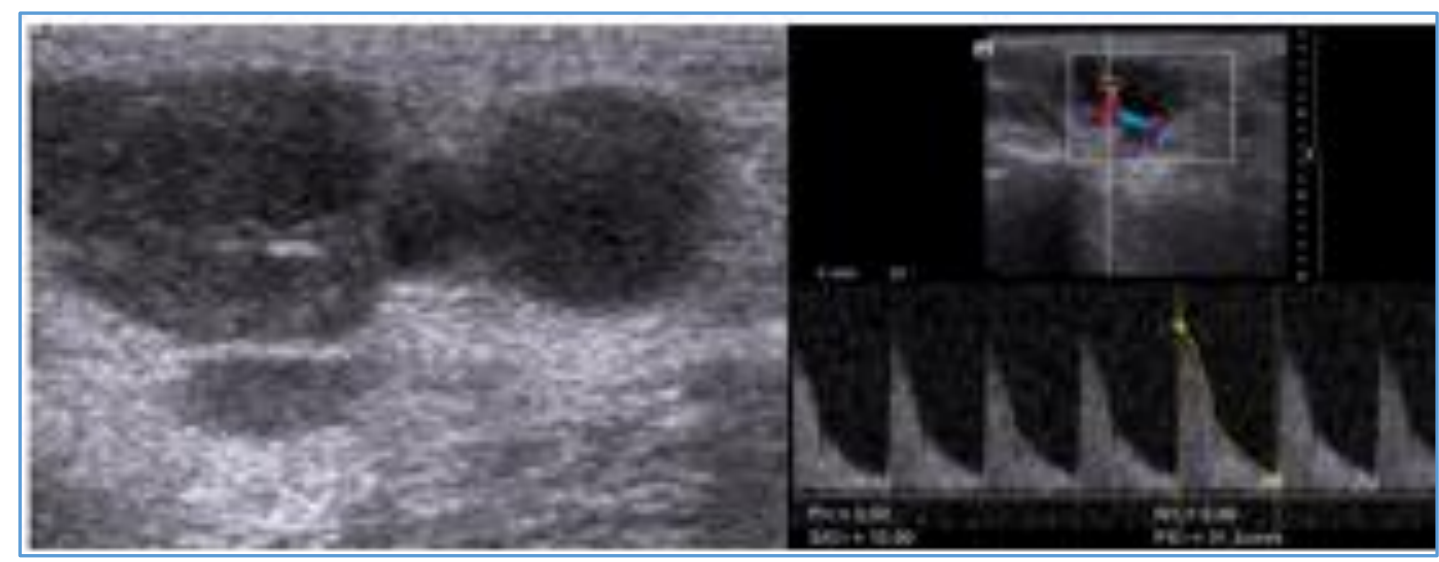

Figure 2A \& B. Histological proven case of Malignancy reveal Small, Round, Well-Defined Hypoechoic Lymph Node and other adjacent Lymph Node is markedly Hypoechoic with Ill-Defined Borders (Figure A); on Pulse Doppler, which shows Peripheral Vascularity with High Resistance Flow (0.9) in Figure B

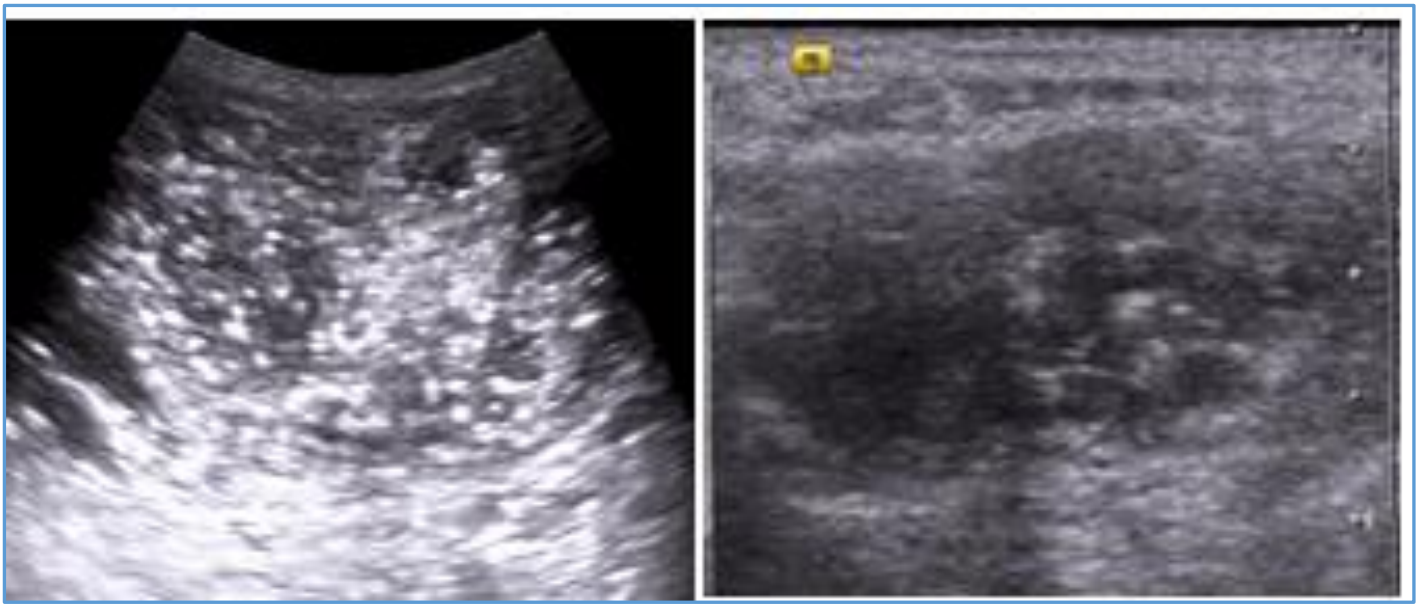

Figure 3A \& B. Histological proven case of Papillary Carcinoma of Thyroid reveal Large Thyroid Lesion having Multiple Calcifications (Figure A) and Metastatic Lymph Node having Punctuated Calcification (Figure B) 


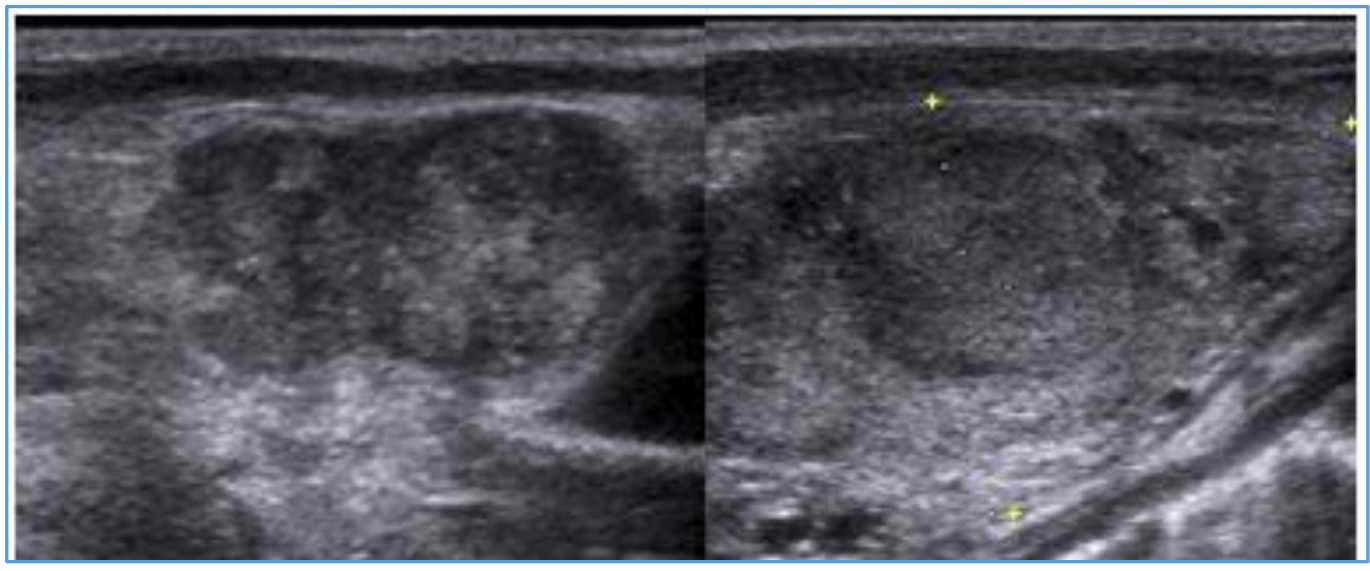

Figure 4. HRUS reveal Metastatic Lymph Node having Focal Cortical Nodules

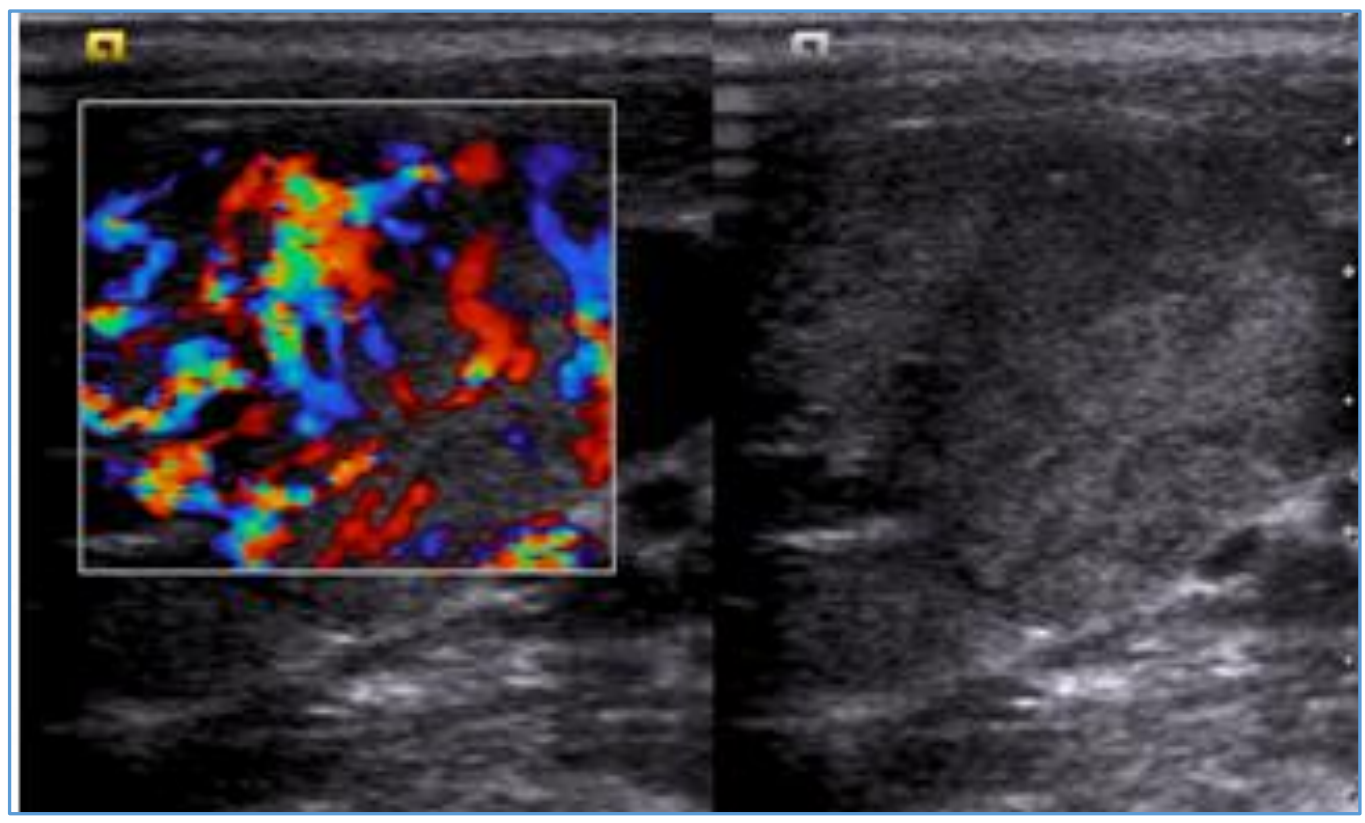

Figure 5. HRUS with Colour Doppler reveal Well-Defined Enlarged Lymph Node showing Chaotic type of Vascular Pattern in known Case of Malignancy

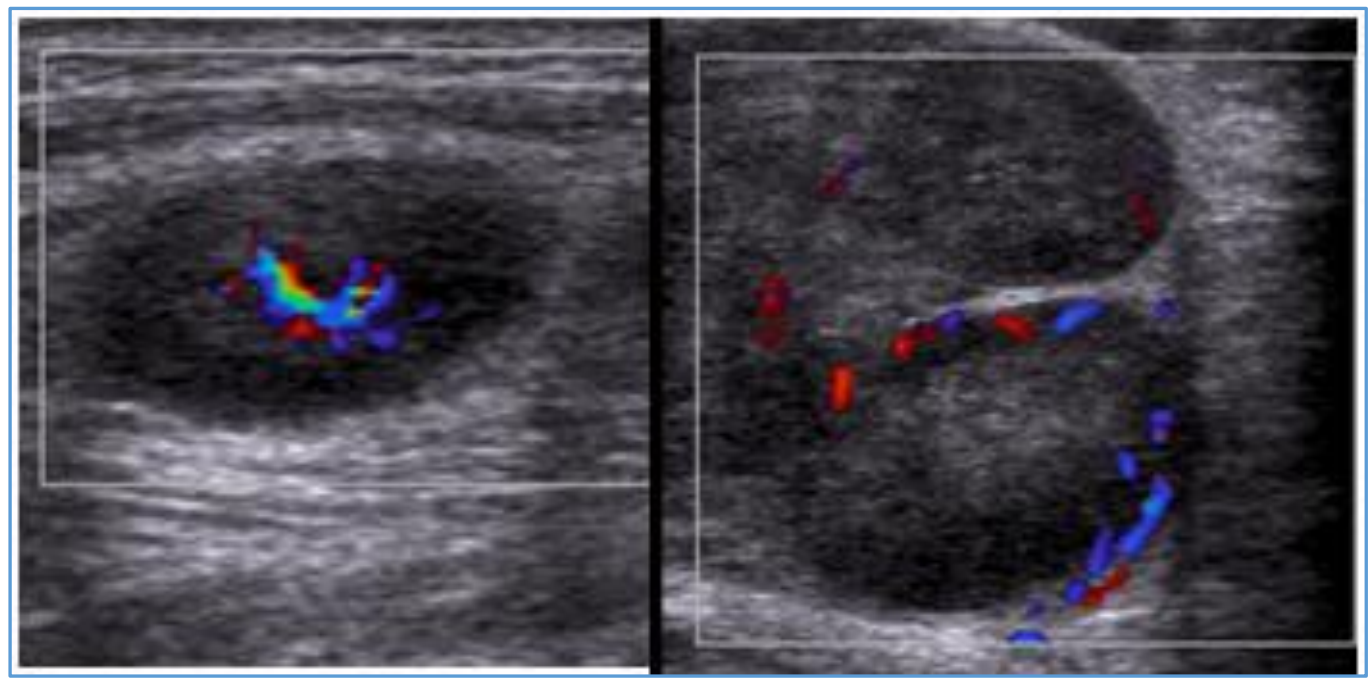

Figure 6A \& B. Colour Doppler reveal Well-Defined Oval Shape Lymph Node showing Central Type of Vascular Pattern in Benign Case (Figure A), while Peripheral Vascular Pattern in Malignant Lymph Node (Figure B) 


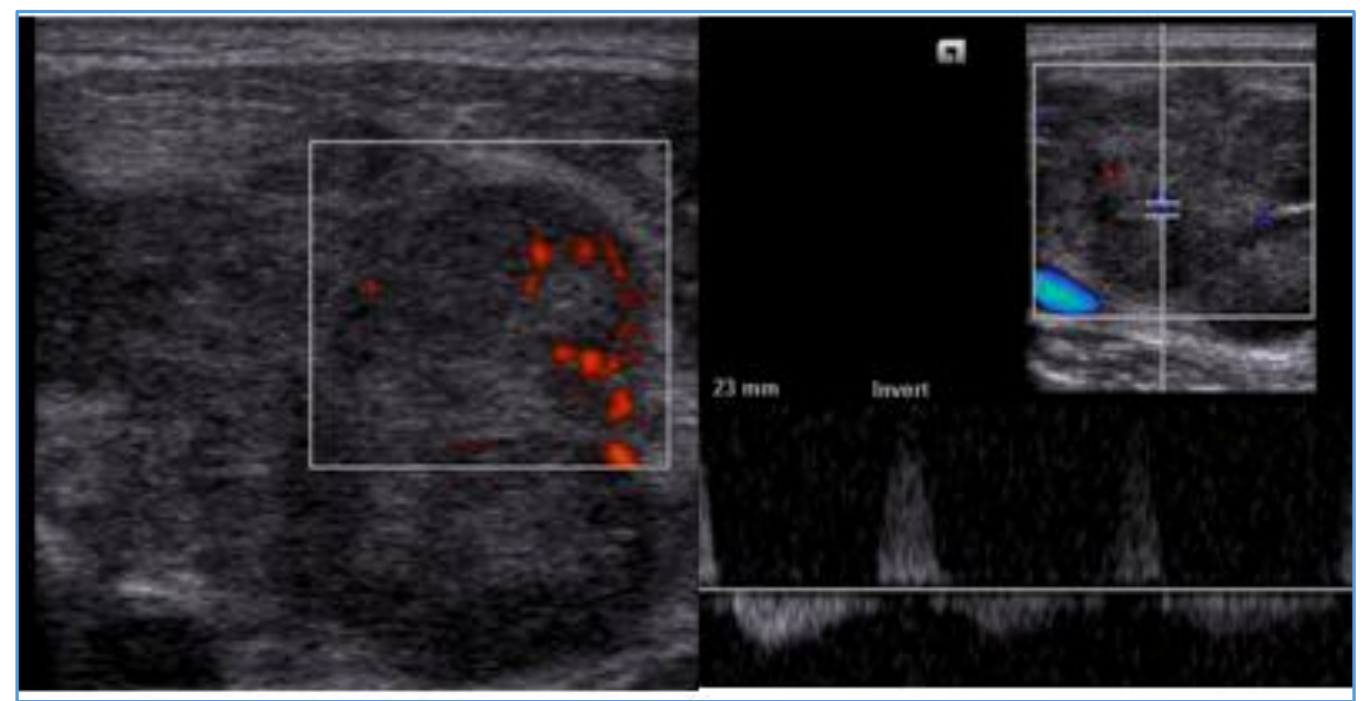

Figure 7. HRUS and Colour Doppler reveal Well-Defined Matted Lymph Nodal Lesion showing Central and Peripheral Vascular Pattern with High Resistance Flow in Case of Lymphoma

\section{DISCUSSION}

\section{Size}

Size of a lymph node can be increased due to benign inflammatory process or secondary to malignancy. Although, incidence of malignancy was observed more in large lymph nodes, but benign inflammatory process may cause enlarged reactive LN. Obviously, enlarged size alone cannot be a reliable feature for malignancy. Van Den Brekel et al[5] found that the size of a lymph node is not an accurate predictor of metastasis, at least in N0 location of neck. Minimum axial diameter of normal and reactive lymph nodes is $9 \mathrm{~mm}$ for subdigastric and submandibular nodes, and $8 \mathrm{~mm}$ for other cervical lymph nodes yielded overall accuracy of $75 \%$. According to Ying $\mathrm{M}$ et al, the diagnostic sensitivity increases when lower cut-off value of lymph node size is used but the specificity decreases.[6] In our study, the axial diameter (short axis diameter) $>10 \mathrm{~mm}$ was taken as the ultrasound criteria for malignant involvement of lymph nodes. Total 110 lymph nodes were examined in our study, out of them 96 were $>10$ $\mathrm{mm}$ in short axis, of which 24 lymph nodes were found to be malignant on HPE. This criteria yielded high sensitivity (88.8\%), but low PPV (25\%) and worse the specificity (14\%).

\section{Shape}

Benign lymph nodes are usually oval or elongated in shape and malignant lymph nodes are often rounded in shape. The ratio of long axis diameter to short axis (L/S) or short axis to long axis ratio $(\mathrm{S} / \mathrm{L})$ is used to assess shape of a lymph node, also known as roundness index. A round shape lymph node shows $\mathrm{L} / \mathrm{S}<2$ (or $\mathrm{S} / \mathrm{L}<0.5$ ). Steinkamp et al[7] in their study found that histologically proven $95 \%$ benign LNs were showing L/S ratio $>2$ and 95\% malignant LNs were showing $\mathrm{L} / \mathrm{S}$ ratio $<2$. Solbiati $\mathrm{L}$ et al found $\mathrm{L} / \mathrm{S}$ ratio criteria highly sensitive in diagnosis of malignant lymphadenopathy.[8] In our study, $96 \%$ round shape $(\mathrm{L} / \mathrm{S}<2)$ lymph nodes were found to be malignant on HPE with high sensitivity (96.2\%), specificity (84.3\%) and accuracy (87.2\%).

\section{Hilum}

An echogenic hilum indicates benign nature, while malignant LNs do not show echogenic hilum. ${ }^{[8]}$ However, echogenic hilum may be found in malignant LNs. ${ }^{[9]}$ In our study, $70 \%$.
Lymph nodes showing no visible hilum was found to be malignant on HPE, The PPV, NPV, sensitivity, specificity and accuracy of absence of hilum were $71 \%, 91 \%, 97 \%, 92,89 \%$ and $90 \%$ respectively.

\section{Echogenicity}

Metastatic lymph nodes are hypoechoic compared to neighbouring strap muscles.[10] Echogenic lymph nodes are encountered in metastatic papillary or medullary thyroid carcinoma due to intra-nodal thyroglobulin deposits.[11] In our study, markedly hypoechoic criteria yielded sensitivity of $74 \%$, specificity of $96 \%$ and accuracy of $90 \%$.

\section{Margins}

Benign lymph nodes are characterised by sharp margins; however, irregular or angular margins represent a suspicion of metastasis.(12) According to Ahuja AT et al, nodal border alone is not a reliable criteria; however, the presence of illdefined borders in a proven metastatic node indicates extracapsular spread. In our study, ill-defined margin as a feature of malignancy have high specificity of (83\%) and low sensitivity of $(25 \%)$.

\section{Internal Structural Changes- Table 3 Calcification}

Calcification is uncommon in lymph nodes; however papillary carcinoma from thyroid tend to show calcification in metastatic cervical lymph nodes.[13] Ahuja AT et al[14] in their study found that punctate, peripheral calcification with posterior acoustic shadowing observed in metastatic lymph nodes in papillary carcinoma of thyroid is usually seen in high resolution sonography. Metastatic lymph nodes from medullary carcinoma may also show calcification, but its incidence is substantially lower than papillary carcinoma of thyroid. In our study, only one malignant lymph node revealed calcification.

\section{Necrosis}

Intranodal necrosis is a non-specific feature, as it may be found in chronic infectious conditions like tuberculosis as well. In our study, intranodal necrosis taken as a criterion for malignancy revealed PPV of 24\%; however, countries like 
India where prevalence of infectious diseases like tuberculosis is high, necrosis may be associated with chronic infections. In this regard, necrosis considered as a benign feature possessed PPV of $76 \%$.

\section{Colour Doppler Features- Table 4 Vascular Pattern}

Reactive lymph nodes show central vascularity, while peripheral or mixed vascularity are feature of metastatic LNs. Peripheral vascularity in a metastatic LN indicates tumour infiltration and angiogenesis. In our study, peripheral and mixed vascularity (combined) has a PPV of 63\%, NPV 94\%, sensitivity $85 \%$, specificity $84 \%$ and accuracy $85 \%$.

\section{Flow Impedance}

Theoretically, low resistance produced by vasodilatation is encountered in inflammatory aetiology, while vessel compression by tumour cells leads to increased resistance in malignancy. Some studies shown higher RI val. Ahuja AT et al, in their study reported the cut-off value of 0.7 for RI yielded a sensitivity of $86 \%$ and a specificity of $70 \%$ for PI, the cut-off value of 1.4 had a sensitivity of $80 \%$ and a specificity of $86 \%$.[15] In our study, 37 lymph nodes revealed RI of $>0.8$, of which 22 were positive for malignancy. RI $>0.8$ as criteria for malignancy possessed a PPV of $59 \%$, NPV 93\%, sensitivity $81 \%$, specificity $82 \%$ and accuracy $82 \%$. Similar to resistive index, PI also increases in malignant lymph nodes. In our study 34 lymph nodes revealed PI > 1.4, out of them 21 were found to be positive on HPE, taken this criteria for malignancy will have PPV 61\%, NPV 92\%, sensitivity 77\%, specificity $84 \%$ and accuracy $83 \%$.

\section{CONCLUSION}

In our study, we found that enlarged size alone is not a predictor of malignancy, a small size LN can be malignant. Roundness index is a useful criterion that yielded 96\% sensitivity, but this criterion has $98 \%$ negative predictive value. Hypoechogenicity and calcification were found to be non-specific features can be present in chronic infectious diseases as well. Absence of hilum and vascular pattern revealed high negative predictive value in differentiation of benign from malignant lymph nodes. Thus, no individual ultrasound feature was found accurate in diagnosis of malignant cervical lymphadenopathy, but association of these features produces highly suggestive appearance in most nonmalignant cases.

\section{REFERENCES}

[1] Som PM. Detection of metastasis in cervical lymph nodes: CT and MR criteria and differential diagnosis. AJR Am Roentgenol 1992;158(5):961-9.
[2] Rubaltelli L, Proto E, Salmaso R, et al. Sonography of abnormal lymph nodes in vitro: correlation of sonographic and histologic findings. AJR Am J Roentgenol 1990;155(6):1241-4.

[3] De Jong BRJ, Rongen RJ, Lameris JS, et al. Metastatic neck disease. Palpation vs ultrasound examination. Arch Otolaryngol Head Neck Surg 1989;115(6):68990.

[4] Esen G. Ultrasound of superficial lymph nodes. Eur J Radiol 2006;58(3):345-59.

[5] Brekel VDMW, Castelijns JA, Snow GB. The size of lymph nodes in the neck on sonograms as a radiologic criterion for metastasis: how reliable is it? AJNR Am J Neuroradiol 1998;19(4):695-700.

[6] Ying M, Ahuja A, Metreweli C, et al. Diagnostic accuracy of sonographic criteria for evaluation of cervical lymphadenopathy. Journal of Utrasound in Medicine 1998;17(7):437-45.

[7] Steinkamp HJ, Muffelmann M, Bock JC, et al. Differential diagnosis of lymph node lesions: a semiquantitative approach with colour doppler ultrasound. Br J Radiol 1998;71(848):828-33.

[8] Solbiati L, Cioffi V, Ballarati E, et al. Ultrasonography of the neck. Radiol Clin North Am 1992;30(5):941-54.

[9] Evans RM, Ahuja A, Metreweli C, et al. The linear echogenic hilus in cervical metastatic lymphadenopathy-a sign of benignity or malignancy? Cli Radiol 1993;47(4):262-4.

[10] Brekel MWVD, Stel HV, Castelijns JA, et al. Cervical lymph node metastasis: assessment of radiologic criteria. Radiology 1990;177(2):379-84.

[11] Ahuja AT, Ying M. Sonographic evaluation of cervical lymph nodes. AJR Am J Roentgenol 2005;184(5):16919.

[12] Saiag P, Bernard M, Beauchet A, et al. Ultrasonography using simple diagnostic criteria vs palpation for the detection of regional lymph nodes metastases of melanoma. Arch dermatol 2005;141(2):183-9.

[13] Som PM. Lymph nodes of the neck. Radiology 1987;165(3):593.

[14] Ahuja AT, Chow L, Chick W, et al. Metastatic cervical nodes in papillary carcinoma of the thyroid: ultrasound and histological correlation. Clin Radiol 1995;50(4):229-31.

[15] Ahuja AT, Ying M, Ho SS, et al. Distribution of intranodal vessels in differentiating benign from metastatic neck nodes. Clin Radiol 2001;56(3):197201. 